\title{
El castigo en el contexto de sociedades sin ley \\ Punishment in lawless societies
}

\author{
Ilsse Carolina Torres Ortega \\ Universidad de Alicante \\ iiilsse@hotmail.com
}

Recibido / received: 06/08/2016

Aceptado / accepted: 15/09/2016

DOI: http://dx.doi.org/10.20318/eunomia.2016.3280

\begin{abstract}
Resumen
En este trabajo se realiza una breve reflexión acerca del castigo en contextos en los que no es posible garantizar la efectividad del sistema jurídico. El cumplimiento de las normas jurídicas implica renunciar a la satisfacción de ciertos intereses, pero esa renuncia ha de tener lugar en el marco de una práctica en la que confiemos en que otros individuos también lo harán, evitándose así conflictos y favoreciéndose la cooperación entre los miembros de la sociedad. El castigo, en este sentido, constituye una técnica de motivación para que, aquellos que no deseen sufrirlo, actúen en conformidad con las normas, así como un respaldo para las víctimas que han sufrido un daño indebido. El castigo es una institución abierta a la discusión moral por los males involucrados en ella y, por tanto, requiere de una fundamentación. Una adecuada fundamentación exige tener en cuenta las consecuencias de la institución y esto, obviamente, presupone que, de hecho, se castiga cuando se dan las condiciones exigidas por la normativa penal. Castigar cuando es jurídicamente debido sería la forma de prevenir la impunidad, pero también de evitar el castigo de inocentes. Impunidad de los actos delictivos y falta de inmunidad ante el castigo en caso de ser inocente serían así los ejes negativos que caracterizarían al castigo en un contexto anómico.
\end{abstract}

\section{Palabras clave}

Castigo, observancia de normas jurídicas, incumplimiento de normas jurídicas, anomia, impunidad.

\begin{abstract}
In this work I did a brief reflection about the punishment under contexts where is not possible to guarantee the effectiveness of the legal system. The observance of legal rules implies giving up on certain interests. This renounce happens in a practical frame where we trust that other individuals will also give up on some of their own interests. By doing so, one avoids conflicts and eases the cooperation between the members of the society. Punishment, in this context, represents a motivational technique for those who do not want to suffer it so they behave according to the rules, as well as a support for the victims who have suffered from any damage. Moreover, the punishment is an open institution for moral discussion due to the problems involved, and therefore it demands a justification. A proper justification requires taking into account the consequences of the institution, and this assumes that a punished individual meets the required conditions for the criminal law. To punish when legally due will prevent impunity and punishment of innocents. The impunity in criminal acts and the lack of innocent's immunity from damage are the negative axes that characterize punishment in an anomic context.
\end{abstract}

\section{Keywords}

\footnotetext{
${ }^{1}$ Agradezco a Isabel Lifante, Victoria Roca y Alí Lozada sus comentarios y conversaciones sobre este trabajo.
} 
Punishment, law compliance, law violation, anomie, impunity.

SUMARIO 1. Introducción. 2. La institución jurídica del castigo. Primera aproximación a los problemas envueltos en un sistema de justicia penal afectado por la anomia. 3. La protección de intereses mediante normas jurídicas: el seguimiento de reglas por parte de los ciudadanos y de las autoridades. 4. El problema de la anomia. 4.1. La anomia general y la inobservancia de normas. 4.2. La anomia en el ámbito del Derecho penal. 4.3. Ciudadanos anómicos. 4.4. Instituciones anómicas. 5. Sociedades anómicas y sus -graves-consecuencias en la justificación del castigo. Conclusiones. 6. Bibliografía.

\section{Introducción}

El término "castigo" ocupa un lugar destacado en nuestras vidas; lo utilizamos en diversas situaciones que se dan de forma habitual tanto en el ámbito social como en el personal, y que ponen de manifiesto la existencia de distintos sentidos de la expresión ${ }^{2}$. Así, el término es perfectamente utilizable cuando un padre "castiga" a sus hijos por desobedecer sus indicaciones, cuando un profesor "castiga" a alguno de sus alumnos por interrumpir la clase, o cuando una persona "se castiga" a sí misma por medio del remordimiento.

Hay un sentido de la expresión que, sin duda, nos produce mayores inquietudes: el castigo como aplicación de sanciones jurídicas y, particularmente, el castigo penal (pena) que involucra sufrimiento deliberado, infligido por parte de autoridades constituidas precisamente para ello. Este es el tipo de castigo que nos interesa a nosotros como estudiosos del Derecho, aunque no sólo a nosotros: el castigo jurídico es también foco de atención de la ciudadanía en general, ya que, aunque en distinta medida, todos somos conscientes de los males involucrados en este tipo de castigo.

Normalmente la toma de conciencia acerca de los riesgos implicados en la institución jurídica de la pena viene generada por la propia convivencia con esta institución y el temor natural de sufrir la privación de algo que consideramos valioso, por ejemplo, nuestra libertad. No obstante, en algunos países parece haber un temor distinto de aquel que surge de la mera advertencia de las consecuencias que siguen a la transgresión de normas jurídicas: la anomia general no permite garantizar una distribución justa de castigos.

En este trabajo realizaré una breve reflexión acerca del impacto que tiene en una institución como el castigo jurídico la condición de ciertas sociedades como "sociológicamente anómicas"3, o dicho con un lenguaje menos especializado,

\footnotetext{
${ }^{2}$ No hace falta recordar que el uso del lenguaje es convencional, por lo que términos tan comunes como "castigo" carecen de un significado correcto que determine el uso que pueda hacerse de él. No obstante, algunos autores como Rabossi han señalado que, pese a esta variedad de casos, es posible identificar algunos elementos comunes: a) existe un individuo que ha actuado mal, en el sentido de haber violado un uso, precepto, directiva o norma; b) hay una persona que tiene sobre el ofensor algún tipo de superioridad (o poder, al menos en el sentido de que podemos influir en la conducta de otro) para aplicar el castigo; c) ese castigo implica un estado de cosas que involucra dolor o sufrimiento por acción directa sobre él o por la privación de bienes que le son valiosos (Rabossi, 1976, p. 185).

${ }^{3}$ El término "anomia", si bien se emplea en un sentido ordinario como "sociedades sin ley", tiene un sentido más específico en el ámbito de la Sociología. El término fue acuñado por Émile Durkheim, y, aunque no desarrolló una teoría de la anomia en un trabajo específico, realizó diversos planteamientos sobre ésta en obras como La división del trabajo social, El suicidio, Lecciones de Sociología, La Educación moral y Las reglas del método sociológico. La anomia en la obra de Durkheim hace referencia a una escisión en la relación entre los individuos y los procesos sociales, ocasionando una
} 
sociedades en las que las normas e instituciones están notablemente debilitadas. Al hablar de estas sociedades estoy pensando especialmente en aquellas que pertenecen al "mundo latino" y ello por ser países cuya dinámica jurídica se ve afectada por la anomia a la par que se mantienen las expectativas propias de un Estado de Derecho ${ }^{4}$.

Para desarrollar lo anterior, en el segundo apartado de este trabajo señalaré algunos de los elementos básicos del castigo en el contexto jurídico. También me ocuparé, si bien brevemente, del problema de la justificación del castigo, dando cuenta de algunas razones tradicionalmente invocadas tanto para legitimar la existencia de una institución cuyo rasgo distintivo es infligir sufrimiento, como para legitimar los criterios de su distribución; esto es, tanto del problema de la justificación del castigo como institución, como de establecer cuándo un acto particular de castigar se puede considerar justo. Entre las razones que contribuyen a legitimar el uso de la fuerza ante transgresiones jurídicas destacaré la protección de expectativas de cumplimiento de las normas. En este sentido, en el tercer apartado, indagaré qué supone la idea del desarrollo de una práctica estabilizadora de conductas, y con ello de expectativas, para después ver las consecuencias que sobre tal práctica tiene la afirmación fáctica de que una gran cantidad de individuos de la sociedad no la observan al incumplir las normas jurídicas. Corresponderá entonces, en el apartado cuarto, abordar algunos aspectos de la anomia generalizada y, sobre todo, de la anomia en el sistema de justicia penal. Este recorrido me permitirá plantear, en un último apartado (apartado quinto), el problema central sobre el que deseo reflexionar en este artículo: las consecuencias que tiene el fenómeno de la anomia, definitorio de las "sociedades sin ley", en la justificación del castigo como institución que, no obstante, sigue funcionando dentro de dichas sociedades.

\section{La institución jurídica del castigo y su fundamentación. Primera aproximación a los problemas envueltos en un sistema de justicia penal afectado por la anomia}

\footnotetext{
falta de interacción social que finalmente desemboca en la obtención de resultados sociales repetidos ineficaces. La anomia en esta concepción sólo se entiende asociándola a la concepción sobre la integración social, ya que Durkheim consideró que esta integración constituye la condición para la existencia de la sociedad y la vida social; su ausencia sería la anomia y destruye la posibilidad de dicha sociedad. La integración no hace referencia únicamente a un respeto formal por el orden establecido, sino que implica una participación en la vida social que, precisamente, no se da en la anomia. En palabras de Durkheim: "Puesto que la forma definida que con el tiempo toman las relaciones que se establecen espontáneamente entre las funciones sociales es la de un conjunto de reglas, cabe decir, a priori, que el estado de anomia es imposible donde quiera que los órganos solidarios se hallan en contacto suficiente y suficientemente prolongado" (Durkheim, 1982, p. 433).

${ }^{4} \mathrm{Al}$ centrarme en el mundo latino no pretendo sugerir que las dinámicas anómicas sean exclusivas de dichos países, sino que su forma de gobierno democrática y de Estado constitucional los compromete con ciertas garantías y con la expectativa de constituir sociedades justas. El estado de Derecho se caracteriza por las siguientes propiedades: las normas jurídicas que se observan deben ser de índole general, tender a la universalidad, deben ser en general irretroactivas, ser estables, ser públicas, ser lo más definidas que sea posible, los hechos condicionales deben ser empíricamente verificables, las normas deben ser aplicadas estricta e imparcialmente a los casos particulares, aplicadas por órganos independientes a quienes las han dictado (Nino, 1992, p. 38 y 39). Aunque el Estado de Derecho no garantiza por sí mismo valores supremos, sí se relaciona con algunos valores como la seguridad, con el poder predecir las reacciones estatales y sociales, el orden, etc. Sin ellos no puede materializarse una sociedad justa.
} 
En una entrevista relativamente reciente ${ }^{5}$, José Ramón Cossío, uno de los once ministros de la Suprema Corte de Justicia en México, manifestó lo siguiente: "Hay países donde la justicia puede tardar un tiempo, ser intrincada... pero a fin de cuentas llega. En cambio, el problema en México es que un número muy grande de delitos, no sólo homicidios y desapariciones, no tienen castigo. En algunos casos ni siquiera se abren los procesos de investigación; en otros, se abren tan defectuosamente que no hay modo de llegar a una solución... En ese sentido creo que hay una desesperanza importante hacia los sistemas de justicia en el país". Pues bien, que éste sea el análisis de uno de los integrantes del sistema judicial de máxima jerarquía en este país es, sin duda, revelador. Aun cuando sólo se trate de una declaración hecha a la prensa, las palabras del ministro ponen de manifiesto una situación generalizada que se percibe respecto de los delitos cometidos en México y que, por ello, es conveniente analizar. La Encuesta Nacional de Victimización y Percepción sobre Seguridad Pública de 2015 (ENVIPE), también de México, estimó una tasa de 28,200 víctimas por cada 100,000 habitantes durante 2014 y, lo que es aún más alarmante, la cifra negra de delitos no denunciados o que no llegaron a averiguación previa supuso un porcentaje del $92.8 \%$-sólo se denunció el $10.7 \%$ y, de estos, un porcentaje menor llegó a investigarse-. Entre los principales motivos para no denunciar, que figuran en dicha encuesta, destacan que tal acto es considerado como una pérdida de tiempo, y también la desconfianza a las autoridades ${ }^{6}$.

Lo anterior es solamente un ejemplo de la realidad que actualmente viven muchos países en los que el castigo ha dejado de representar para la población una institución confiable. La percepción negativa de la comunidad es, no obstante, sólo una parte de la problemática, ya que el castigo es una institución mucho más compleja. Para poder dar cuenta de esta complejidad, es conveniente, en primer lugar, elucidar el concepto de castigo; así, podremos identificar sus principales elementos y las dificultades que presentan.

A lo largo de la historia de las ideas se han ido ofreciendo definiciones que pretenden identificar los criterios de aplicación del término castigo. La mayoría de ellas parecen esconder un propósito mucho más ambicioso y, sin embargo, cuestionable: ofrecer los criterios de legitimidad de esta institución, ya sea descubriendo la esencia imperecedera del castigo $^{7}$, o bien, estableciendo una barrera definicional que, artificiosamente, determine en qué casos estamos ante algo que puede ser llamado castigo y que, por definición, está justificado ${ }^{8}$.

\footnotetext{
${ }^{5}$ Cossío, José Ramón. "La impunidad en México es un problema creciente". El País (España), 27 de octubre de 2015.

${ }^{6}$ Para consultar esta información: http://www.inegi.org.mx/est/contenidos/proyectos/encuestas/hogares/regulares/envipe/

${ }^{7}$ Hay muchos teóricos que, aunque abiertamente abrazan una visión conceptualista, implícitamente continúan viendo en la tarea conceptual un fin en sí mismo que permite comprender en su totalidad una institución. En el caso particular del castigo, muchas controversias se han estancado en la discusión de un concepto que logre dar cuenta de las condiciones de la responsabilidad penal, del delito y de la pena, cuando lo que sucede es que gran parte de la determinación de cada uno de estos conceptos depende de los principios y conclusiones normativas que desarrollemos previamente. Nino nos sugiere una forma de salir de esta encrucijada adoptando un enfoque de sucesivas aproximaciones dialécticas: comenzar con conceptos pre-teóricos de delito y de pena; encarar con ellos la discusión de principios justificatorios; detectar a través de tal discusión las propiedades relevantes para constituir una teoría sustantiva adecuada; definir en forma más precisa los conceptos en cuestión, pero, esta vez, tomando en cuenta aquellas propiedades; usar el nuevo esquema conceptual más refinado para someter a un escrutinio más intenso los principios sustantivos de la teoría, etc." (Nino, 1994, p. 35).

${ }^{8}$ La barrera definicional se refiere a la situación en que una persona evade el tener que dar argumentos sobre la fundamentación de un caso concreto como caso de castigo, aduciendo que, por
} 
En mi opinión, y a los efectos de una mejor comprensión de la institución, es conveniente comenzar ofreciendo una definición que sea lo más descriptiva y exhaustiva posible, al menos en el sentido de que no contenga un pronunciamiento sobre su legitimidad. Decir que sea "lo más descriptiva y exhaustiva posible" supone que no podemos desconocer que tal concepto tendrá, necesariamente, un componente normativo, si bien queda abierto al debate moral cuáles hayan de ser las condiciones de su satisfacción; esto es, qué condiciones exactas habrá de cumplir una determinada medida para ser no solo castigo sino un castigo justificado ${ }^{9}$.

Una definición que se acerca mucho a lo que se ha señalado es la de Herbert Hart ${ }^{10}$, quien propuso una caracterización del caso estándar del castigo que resulta muy esclarecedora para identificar los elementos generales que distinguen a esta institución jurídica: 1) Debe involucrar dolor u otras consecuencias normalmente consideradas no placenteras, o desagradables; 2) tiene que ser por una transgresión a reglas jurídicas; 3 ) tiene que ser aplicado a un real o supuesto delincuente por su transgresión; 4) tiene que ser administrado intencionalmente por seres humanos distintos del delincuente y; 5) debe ser impuesto y administrado por una autoridad constituida por el sistema jurídico en contra del cual se cometió la transgresión (Hart, 2008: 4 y 5).

La elucidación del concepto de castigo, tal como se mencionaba, no resuelve el problema de su justificación. Naturalmente podríamos cuestionar por qué es necesario lo anterior si se trata de una institución milenaria cuya ausencia en nuestras sociedades parece casi inimaginable. No obstante, la práctica del castigo es moralmente relevante: el castigo jurídico supone dibujar una línea que divide a las personas entre delincuentes y observadores de la ley. Quienes caen bajo una de estas categorías reciben un trato que involucra un daño deliberado que es autorizado y administrado por el propio Derecho, mientras que, respecto de los individuos que caen en la otra categoría, dicho trato -esto es, castigar a quien ha observado la ley y es, en este sentido, inocente- se nos presenta como moral y jurídicamente inadmisible. En el hecho de que castigar supone infligir un mal es en lo que radica la relevancia moral de la pena y la necesidad, entonces, de reflexionar y fundamentar por qué en un caso el castigo nos parece algo legítimo y en otro no.

definición, no puede estar justificado porque no se dan los elementos suficientes para hablar propiamente de castigo.

9 Así, pretendo partir de una estrategia parecida a la que sugiere Macario Alemany respecto del problema del concepto y la justificación del paternalismo. Alemany sugiere que en la caracterización del concepto no debe hacerse una valoración: "De esta manera, se evita el riesgo de dar con soluciones a problemas morales que descansen en definiciones, pues resulta inaceptable que se le dé una respuesta negativa al problema de si es correcto desde el punto de vista moral ejercer el paternalismo, diciendo que se trata precisamente de "paternalismo" y el "paternalismo" por definición está injustificado. Entiendo, en consecuencia, que el concepto de paternalismo es "neutral" cuando la afirmación 'A ejerce paternalismo sobre B" no conlleva necesariamente el juicio moral "A está actuando inmoralmente con respecto a B'" (Alemany, 2006, p. 344).

${ }^{10}$ Es preciso señalar que la definición propuesta no fue originalmente ideada por Hart; la versión original fue propuesta por Antony Flew en un trabajo de 1954 titulado "The Justification of Punishment". Asimismo, Hart reconoció también la influencia de S. I. Benn, particularmente por su trabajo "An Approach to the Problems of Punishment" publicado en 1958, en el cual Benn aceptó los criterios del uso de la palabra en su sentido primario propuestos por Flew. Hart señaló, además del caso central del castigo, otras posibilidades como casos sub-estándar o secundarios: a) castigos por infracciones de reglas jurídicas impuestas o administradas por personas distintas de los funcionarios (sanciones descentralizadas), b) castigos por infracciones a reglas u órdenes no jurídicas (castigos en una familia o escuela), c) castigos indirectos o colectivos a algún miembro de un grupo social por sanciones hechas por otros sin la previa autorización, estímulo, control o permiso, y d) castigo de personas (distintas de las incluidas en (c)) que no son ni de hecho ni supuestamente transgresores (Hart, 2008, p. 5). Considerando estos casos secundarios, Hart evidenció que no obviaba el uso ordinario del término, sino que pretendía centrar su análisis en el contexto jurídico. 
Tradicionalmente, la justificación del castigo se ha intentado explicar por medio de dos grupos de teorías que han caracterizado posiciones morales enfrentadas: las teorías deontologistas o retribucionistas y las consecuencialistas, utilitaristas o prevencionistas. Deontologismo y consecuencialismo son dos tradiciones que representan grandes concepciones morales del pensamiento occidental moderno que se enfrentan en muchas cuestiones; ahora bien, en pocos casos se enfrentan tan sustancialmente como en el castigo. En relación con este debate, durante mucho tiempo se ha hablado de retribucionismo y de prevencionismo como dos teorías distintas y confrontadas a la hora de justificar esta institución ${ }^{11}$.

Aunque muchos teóricos han insistido $-y$ continúan insistiendo- en que estas teorías tradicionales representan un genuino dilema que nos fuerza a optar por un grupo u otro de razones para mantener una teoría coherente, sucede, sin embargo, que en ambas existen asunciones sobre la pena a las que difícilmente estaríamos dispuestos a renunciar ${ }^{12}$. Desarrollemos esto.

Por un lado, la concepción retribucionista enfatiza la responsabilidad moral del individuo que ha causado el mal; por ello, su culpabilidad es la medida de su pena, puesto que el mal que supone el castigo debe ser proporcional al mal que ha causado. Bajo esta concepción, la justificación de la pena no puede tomar en cuenta las consecuencias que se obtengan de su aplicación, al considerar que, de otra forma, el individuo corre el riesgo de ser instrumentalizado. Así, se considera que esta posición permite excluir la posibilidad de penar a un inocente o castigar a alguien que no ha actuado de forma voluntaria, además de que permitiría explicar por qué un acto de mayor gravedad es susceptible de recibir un castigo también más grave. Aunque esto, en principio, nos parece adecuado, esta concepción nos lleva a tener que aceptar algunas asunciones implausibles, como la creencia irracional acerca de que la suma de dos males produce un beneficio intangible, o la relevancia de evaluar el carácter moral del delincuente ${ }^{13}$.

El prevencionismo, por su parte, enfatiza la importancia de las consecuencias de la pena (descartada por la postura contraria): debe ser un medio efectivo para evitar daños futuros, puesto que el daño cometido ha sido ya realizado y es imposible de "retribuir". Así, esta concepción sostiene que el castigo no debe ser una forma de

\footnotetext{
${ }^{11}$ El enfrentamiento de estos dos grupos de teorías no es nada nuevo. Ya en el diálogo de Platón sobre Protágoras se hacía mención de la dicotomía: "Porque nadie castiga a un hombre malo sólo porque ha sido malo, a no ser que se trate de alguna bestia feroz que castigue para saciar su crueldad. Pero el que castiga con razón, castiga, no por las faltas pasadas, porque ya no es posible que lo que ha sucedido deje de suceder, sino por las faltas que puedan sobrevenir, para que el culpable no reincida y sirva de ejemplo a los demás su castigo" (Platón, 1871, p. 36). Asimismo, en el debate sobre Mitilene, se ven contrastadas la postura de Cleón -que representaría la posición retribucionista defendiendo la idea de merecimiento, la proporcionalidad y la culpa como reprochabilidad-, y la postura de Diódoto -que representaría la posición consecuencialista, aludiendo a la comprensión y explicación de la conducta delictiva, el cuestionamiento de la culpabilidad como medida del castigo y la utilidad del castigo en el futuro-. No fue hasta el siglo XVIII, tras el trabajo de los pensadores Bentham y Kant, cuando el debate se afianzó en las dos tradiciones señaladas.

${ }^{2}$ En esta tesitura, Nino sugiere que en el fondo de las discusiones sobre la fundamentación filosófica del Derecho penal hay un enfrentamiento entre, por un lado, una concepción general intrínseca a un enfoque liberal y racional de la responsabilidad penal y, por el otro, una serie de convicciones intuitivas (como que un inocente no debe ser penado, que ciertas actitudes subjetivas deben ser tomadas en cuenta, que la tentativa merece un castigo menor, etc.) sobre cuáles son las condiciones y distinciones que un sistema de responsabilidad justo debe tomar en cuenta (Nino, 1980, p. 31).

${ }^{13}$ Determinar que un individuo es merecedor de un castigo implica hacer una evaluación de su acto como manifestación de su carácter moral, es decir, que tal acto refleja qué tipo de persona es. Sobre el acto de culpar a alguien es estos términos, Nino dice lo siguiente: "Si para culpar a alguien se necesita realizar una evaluación de su carácter moral, la culpa necesariamente supone ideales de virtud o excelencia personal... La acción que es el objeto de la culpa degrada el carácter del agente y la calidad de su vida" (Nino, 2006, p. 207).
} 
venganza institucionalizada que no tome en cuenta las consecuencias de su aplicación. No obstante lo anterior, desde esta concepción de justicia podría llegarse a justificar el castigo a un inocente si esto fuera considerablemente beneficioso para la sociedad. Esto es, el utilitarismo legitima que ciertos individuos sean utilizados como simples medios, ya que lo que pone como bien superior es la suma agregada de bienestar.

Con lo anterior queda de manifiesto que ambas posturas poseen evidentes ventajas y desventajas. Por ello, se han considerado otras posibilidades que permitan mantener esas ventajas sin tener que comprometernos con aquellas asunciones que son difícilmente aceptables. En este sentido, la dicotomía es insalvable sólo de manera aparente, ya que puede admitirse una tercera opción que pase por deconstruir el problema del castigo para, a partir de este análisis, identificar en qué parte son necesarias razones morales de tipo deontologista 0 de tipo consecuencialista. Aportaciones como la de Hart, en el área de filosofía del Derecho, han contribuido considerablemente al debate actual sobre la fundamentación del castigo jurídico por esta tercera vía ${ }^{14}$. Este autor planteó la necesidad de diferenciar entre el problema de la justificación de la institución y la distribución $^{15}$ : la prevención del daño, y con ello la protección de las expectativas generadas por las reglas de un sistema jurídico, constituye el fin general justificativo de la institución del castigo; mientras que la aplicación concreta de la pena -es decir, su distribución- tiene que tomar en consideración las tesis retribucionistas para que sólo sufra aquel que es culpable de una transgresión jurídica.

Aunque el problema de justificación moral del castigo es mucho más complejo, para los fines que aquí nos interesan, me parece suficiente haber señalado la importancia de tal debate y las líneas centrales esgrimidas por cada concepción. Esto es relevante para tener presentes, en lo que sigue, las razones que fundamentan la permisión de una práctica que, al consistir en causar daño, sería, prima facie, ilegítima. Es la certeza de que este daño implica un mal menor-comparado con los beneficios generales que pueden alcanzarse por medio de la práctica del castigo- lo que sustenta, en gran medida, la permanencia de esta institución. El corolario de esta aserción es que estamos ante un serio problema cuando el castigo se desarrolla en contextos anómicos, caracterizados por el incumplimiento generalizado de normas y la ineficacia del sistema de justicia. Antes de explicar con mayor detalle lo anterior, es necesario destacar cómo la práctica del castigo juega un papel central en la dinámica jurídica de las sociedades, principalmente, como técnica de motivación en el cumplimiento de las normas y como una forma de proteger los intereses, generales e individuales, de las personas.

\section{La protección de intereses mediante normas jurídicas: el seguimiento de reglas por parte de los ciudadanos y de las autoridades}

\footnotetext{
${ }^{14}$ Evidentemente esto no sólo ha sucedido en el área iusfilosófica. En Derecho penal son bien conocidas las teorías mixtas que también sugieren una combinación de elementos retributivos y prevencionistas en distintos momentos de la tarea penal. En este sentido, resulta ejemplificadora la posición de Roxin: "Nuestro punto de partida es que el Derecho penal se enfrenta al individuo de tres maneras: amenazando, imponiendo y ejecutando penas, y que esas tres esferas de actividad estatal necesitan justificación (Roxín, 1976, p. 20).

${ }^{15}$ En su artículo Prolegomenon to the Principles of Punishment, Hart sugirió diferenciar las cuestiones de definición, el fin general justificativo y la distribución del castigo que implica cuestiones de título y cantidad. Con esta diferenciación quedan de manifiesto los dos principales niveles que observamos en la existencia del castigo en nuestros ordenamientos jurídicos, los cuales posiblemente son la fuente de mayores confusiones: el nivel de la práctica en general y el de la aplicación. Esta última distinción, coincide con la expuesta en 1955 por John Rawls en Two Concepts of Rules.
} 
En lo que sigue haré un recorrido muy básico acerca de cómo entre los miembros de una comunidad jurídica se crean dos tipos de expectativas: unas respecto a que el cumplimiento de normas de conducta implica que se puede esperar lo mismo por parte de los demás individuos, y las otras sobre aquello que se puede esperar por parte de las autoridades cuando las primeras expectativas se vean defraudadas.

Como nos recuerdan Atienza y Ruiz Manero, es un lugar común que la función primaria de cualquier sistema normativo consiste en guiar la conducta de los individuos que lo integran (2007: 115). Para ello, dentro de este sistema hay normas regulativas que establecen permisos y pautas de comportamiento que deben ser observadas (deberes o prohibiciones) ${ }^{16}$. Estas últimas están dirigidas directamente a los jueces e indirectamente $-\mathrm{y}$, sin embargo, centralmente- a los ciudadanos, imponiéndoles limitaciones a la persecución de sus intereses.

Estas normas de conducta fijan ciertas limitaciones a los individuos, estableciéndose una serie de consecuencias jurídicas -entre ellas el castigo- para aquellos casos en los que no se observen dichos límites. Conocer el contenido de estas pautas de comportamiento y saber que los tribunales aplicarán una pena en el supuesto de transgredir alguna de ellas es algo que, normalmente, influye en nuestra forma de interactuar con los demás: el deseo de evitar una sanción funciona como una motivación en el cumplimiento de las normas jurídicas ${ }^{17}$.

Evidentemente, en un ordenamiento jurídico muchos individuos no siguen las normas sólo por el temor a la sanción, sino que las aceptan como pautas de conducta por razones morales. En este orden de ideas, tal y como señala Nino, el Derecho tiene como funciones primarias la de reducir los conflictos sociales y facilitar la cooperación, y esto lo procura a través de la autoridad y la coacción. No obstante, para cumplir satisfactoriamente dichas funciones el Derecho necesita que un número importante de individuos (especialmente entre aquellos que conforman los poderes públicos) acepten el Derecho por la legitimidad moral de sus prescripciones ${ }^{18}$; sin el apoyo de la moral sólo se tendrían razones prudenciales, y esto no suele ser suficiente para un lograr en un grado eficaz el cumplimiento de dichas funciones (Nino, 1994: 148).

En definitiva, ya sea que se actúe por razones morales o solamente por razones prudenciales, el cumplimiento de las normas implica una aceptación de una práctica que fija normas de conducta y que involucra una serie de reacciones adversas hacia

\footnotetext{
${ }^{16}$ En este sentido, sobre las normas que establecen deberes o prohibiciones (normas de mandato), Atienza y Ruiz Manero establecen lo siguiente: "En las normas de mandato, esta función de guía de conducta se lleva a cabo estipulando, bien la obligación de realizar una determinada acción p en un determinado caso q (o, lo que es lo mismo, la prohibición de omitir realizar $p$ en q), bien la prohibición de realizar $p$ en $q$ (o, lo que es lo mismo, la obligación de omitir $p$ en $q$. Esto es, las normas de mandato, que pueden expresarse bajo la forma de obligaciones o de prohibiciones, ordenan, bien realizar una determinada acción, bien omitirla y, así, deslindan la esfera de lo lícito de la de lo ilícito)" (2007, p. 115 y 116).

17 Aquí me estoy refiriendo sólo al nivel prudencial como el nivel más básico en que el que, conocer cómo actuarán los tribunales en el supuesto de cometer una transgresión al ordenamiento jurídico, es algo que influye en la conducta de los particulares, puesto que, lo más común, es desear evitar la sanción; por lo tanto, la sanción ejerce una función ideológica motivadora para querer cumplir con el Derecho, aunque no es toda la motivación. La fuerza, por supuesto, no es el único criterio de obediencia del Derecho, ya que a pesar de que las normas de conducta regulan la aplicación de la fuerza, no significa que ellas mismas se agoten en dicha regulación. La institucionalización de la fuerza tiende a crear hábitos de conducta que se sienten como debidos $\mathrm{y}$, de no ocurrir de esta forma, el sistema jurídico no cumple su función a nivel psicológico y no se vive como un orden jurídico, sino como un dictado de la fuerza (Ross, 1994).

${ }^{18}$ Este juicio de legitimidad requiere en última instancia de juicios extrajurídicos, es decir, juicios morales convergentes acerca de la legitimidad moral de las prescripciones jurídicas (Nino, 1994, p. 158).
} 
quienes no se ajusten a éstas. Seguir tal práctica, es decir, el seguimiento de normas de conducta involucra a veces la renuncia, al menos parcial, a ciertos intereses, y viene unido tanto a la confianza de que otros también las obedecerán, renunciando a su vez a algunos de sus intereses, como a la seguridad de que aquellos que no cumplan con lo anterior serán castigados ${ }^{19}$. La aceptación mencionada implica modificar las propias preferencias o, en su caso, si la primera opción de una persona coincide con una preferencia que permite la cooperación, dicha aceptación es una forma de reafirmar que sus expectativas respecto de la conducta de otros son apropiadas.

Considerando que este orden de preferencias no suele ser aceptado espontáneamente por todos los miembros de una sociedad, el Derecho hace uso de sanciones -positivas y negativas ${ }^{20}$ - para lograr que las preferencias individuales coincidan con ese orden. De modo que, el papel que cumplen dichas sanciones es el de constituir razones adicionales para obedecer las normas. Por medio de estas sanciones, el Derecho procura el cumplimiento de sus prescripciones, ya sea prometiendo algún tipo de recompensa para aquellos que cumplan las normas o, en caso contrario, una sanción como el castigo para aquellos que no lo hagan. Más aun, lo anterior implica que la pena, para funcionar como una técnica de motivación, debe ser cierta, esto es, que es necesario tener la certeza de que dichas sanciones se harán efectivas; no basta con que sean anunciadas, sino que deben llevarse a cabo regularmente.

Esta regularidad permite constituir una práctica en la que los individuos confirman que, si adaptan su comportamiento a las normas, los otros también lo harán o habrá consecuencias por ello, sintiéndose protegidos de daños arbitrarios. De esta forma, los individuos desarrollan expectativas acerca del cumplimiento de las normas jurídicas $\mathrm{y}$, de acuerdo con estas expectativas, tal seguimiento será socialmente aceptado, mientras que la transgresión de normas suscitará el reproche entre los miembros de la comunidad. Tener una preferencia por aquellas conductas que traten de adaptarse a ciertos patrones supone reaccionar negativamente hacia los comportamientos que no lo hagan, esto es, que la persona que infringe una norma incurre en la desaprobación de quienes la aceptan y, por ello, desde la perspectiva de quienes la sostienen esta desaprobación está justificada (MacCormick, 2010: 247). Este reproche se ve motivado por la frustración de expectativas, aunque estas se mantienen y se siguen considerando valiosas en la medida en que sean reconocidas por el poder estatal. Lo que quiero decir es que en la dinámica de protección de expectativas resulta crucial que, en caso de transgresión de normas, otras personas, que estén dotadas de ciertas competencias para ser autoridades, intervengan para procurar restaurar un equilibrio entre beneficios obtenidos y daños sufridos que no están respaldados por ninguna norma ${ }^{21}$. Aquí hacemos referencia

\footnotetext{
${ }^{19}$ En este caso es perfectamente posible pensar en normas jurídicas, morales o sociales y en castigos que, en un sentido más amplio, impliquen no sólo los actos de coacción estatal, sino otras consecuencias como la desaprobación moral o el rechazo social.

${ }^{20}$ Sobre la función promocional del Derecho y las sanciones positivas, Pérez Lledó señala que es necesario distinguir entre distintas medidas, ya que ni todas promocionan por igual las mismas cosas, ni todas utilizan las mismas técnicas. Este autor propone distinguir entre el fin a promocionar y las técnicas o medios promocionales, y luego distinguir aquellos que consisten en incentivar o motivar conductas y aquellos que no lo hacen directamente. En este sentido, el autor propone diferenciar cuatro conceptos básicos: premio puro, promesa de premio, incentivo puro y facilitación (Pérez Lledó, 2000 , p. 667). De estos cuatro, sólo la promesa de premio y el incentivo motivan la conducta de forma directa, suministrando razones operativas para la acción.

${ }^{21}$ Una propuesta muy sugerente que enfatiza esta idea es la de John Finnis. Este autor sostiene que el agente se gratifica injustificadamente, ejerciendo autopreferencias que el resto de los ciudadanos que cumplen la ley se niegan; el castigo es una forma de eliminar del delincuente un tipo de ventaja que ha obtenido al haber optado con las preferencias de su propia voluntad en lugar de aquello que contribuye al bien común (Finnis, 1999, p. 100).
} 
ya no a expectativas respecto al comportamiento de los otros miembros de la sociedad, sino a expectativas sobre el funcionamiento del Estado: los individuos esperan que sus intereses, indebidamente afectados, sean defendidos por las instituciones, reconociendo así la desigualdad generada por quienes no han adaptado su conducta a los patrones esperados.

Estos intereses pueden ser de distinto tipo, pero los más valiosos suelen ser protegidos por las normas penales. Por tanto, debemos tener presente que la determinación del ordenamiento jurídico-penal posee peculiaridades respecto de otras normas que también protegen intereses de los individuos. Tal como señala Ripollés, en el caso de la legislación penal nos movemos en el campo del control social jurídico sancionador, y las decisiones que se tomen deben tener en cuenta los datos relevantes de la realidad social y jurídica (Ripollés, 2011: 502) ${ }^{22}$. Atender a lo anterior permite hablar de una actividad legislativa racional que se estructura en distintos niveles de tipo instrumental y de tipo moral $^{23}$, a los que después se incorporan los principios y las reglas penales.

Las reglas de conducta penales prevén castigos para ciertos comportamientos con el objetivo de que no sean realizados. Si bien es cierto que esto puede causar ciertos perjuicios a los individuos, puesto que pueden vivir estas restricciones como obstáculos para la satisfacción de sus planes de vida ${ }^{24}$, dichas limitaciones se refieren a conductas que resultan dañinas para otros, en la medida en que obstaculizan el plan de vida de los demás miembros de la comunidad. La finalidad que se persigue al proscribir estas conductas y anunciar la aplicación de un castigo es disuadir a los individuos de su realización ${ }^{25}$, esto es, jugar un papel en la deliberación de la conducta.

Aunado a lo anterior, también es posible identificar un objetivo secundario cuando una persona ya ha optado por cometer una conducta delictiva, ya que un castigo menor, por ejemplo, puede ofrecer una razón para que tal conducta sea desarrollada de la manera menos lesiva. Si X planea entrar a una casa con la finalidad de robar los objetos valiosos que encuentre en ella, tiene varios caminos para satisfacer su objetivo: entre ellos, tiene la opción de entrar cuando los habitantes no estén presentes. De esta forma, podría apoderarse de los objetos y aunque causaría un daño patrimonial a los habitantes de la casa lo hará sin el riesgo de lastimar su integridad física. En el supuesto de ser descubierto entonces su situación sería más

\footnotetext{
${ }^{22}$ Al respecto agrega lo siguiente: "De un modo u otro la racionalidad legislativa penal supondría el punto de llegada de una teoría de la argumentación jurídica, a desarrollar en el plano del proceder legislativo penal, que garantizara decisiones legislativas susceptibles de obtener amplios acuerdos sociales por su adecuación a la realidad social en la que se formulan" (Ripollés, 2011, p. 502).

${ }^{23}$ En este sentido, Ripollés acepta la propuesta de Manuel Atienza de que la racionalidad legislativa se estructura en cinco niveles: Lingüística, jurídico-formal, pragmática, teleológica y ética. Los primeros cuatro serían de tipo instrumental y el último de tipo justificador. Estas cinco racionalidades estarían, a su vez, afectadas por la dimensión transversal de la eficiencia (Ripollés, 2011, p. 506).

${ }^{24}$ Tal y como señala Ferrajoli, el Derecho penal se manifiesta en la vida de las personas como restricciones. De entre estas restricciones destaca tres que son las que corresponderían a los momentos de la técnica punitiva: la prohibición de ciertos comportamientos para la ciudadanía en general, el sometimiento a juicio penal de quienes sean sospechosos de transgresiones jurídicas, y la represión o punición de los culpables (Ferrajoli, 1995, p. 209).

25 En este sentido, Silva Sánchez agrega que el intento de disuadir a las personas de realizar conductas dañinas se relaciona con la información que tienen acerca de las razones que determinan que dichas conductas den lugar a hechos socialmente lesivos o a hechos positivos. Para ello, se hace el anuncio de las consecuencias negativas que recaerán sobre el sujeto que realice tales conductas lesivas, así como de las consecuencias favorables que se siguen de la realización de ciertas conductas positivas. En el caso concreto de la prevención por normas, además del anuncio de las consecuencias, deben exponerse las razones por las que la conducta se considera lesiva para terceros, además de otros dos elementos adicionales: se le indica a la persona que su deber es no realizar dicha conducta y se le ordena no llevarla a cabo (Silva, 2011, p. 30).
} 
favorable que aquella en la que, además del robo con allanamiento de morada, tuviera que enfrentar un homicidio, por mencionar una posibilidad ${ }^{26}$.

La institución del castigo, como ya se expresó en el apartado anterior, tiene como finalidad general la prevención de estas conductas, por lo que para su fundamentación es necesario que el mal que se evita socialmente sea comparativamente mayor que el mal que se causa a ciertos individuos mediante su aplicación. Es decir, para justificar la institución se necesita, entre otras condiciones que, como resultado de la amenaza y aplicación de castigos, los delitos que se cometen sean significativamente menos de los que habría en tal sociedad si no existiera la institución.

La aplicación de castigos jurídicos corresponde únicamente al Estado. En efecto, nuestras sociedades se caracterizan por el hecho de que el recurso a la fuerza para castigar es monopolio estatal. Por ello, además de las normas deónticas o regulativas, tenemos también las reglas que confieren poderes a determinadas personas. Las normas que confieren poder, aunque no nos indican directamente cómo debemos comportarnos en ciertas circunstancias -algo distinto es que la consecución de un resultado venga caracterizado deónticamente por una norma de mandato (prohibido, permitido, obligatorio) -, sí señalan cómo podemos obtener determinados resultados normativos ${ }^{27}$. Estas reglas no son normas deónticas y no pueden "incumplirse" en el mismo sentido que las normas de mandato. Por tanto, cuando hablamos de autoridades que las transgreden, nos referimos a una situación distinta a aquella en la que hablamos de ciudadanos normales que no observan las normas jurídicas. Más adelante, cuando se aborde el tema de las instituciones anómicas, veremos por qué es relevante tener en cuenta lo anterior.

Estas reglas que confieren poder permiten establecer autoridades y órganos con potestades determinadas para aplicar normas y hacer que las mismas se cumplan, modificando así la situación normativa de alguien. De esta manera, los tribunales tienen la competencia para fijar castigos y asegurar su ejecución, teniendo a su disposición una serie de instrumentos para procurar lo anterior. Hay que tener en cuenta que si bien el Estado posee tal facultad y autoriza a determinados individuos para llevarla a cabo, ésta no es ilimitada: las penas, pese a implicar sufrimiento, deben respetar el estatus de ser humano y agente moral del delincuente y, a la vez, hacer esto compatible con el derecho a la justicia que esperan ver satisfecho aquellos que han sufrido un daño.

Con esto, pretendo resaltar que la práctica de castigar, tanto para la víctima como para el delincuente, está muy lejos de ser un mero "trámite burocrático" realizado ante autoridades. El juicio ofrece al acusado la oportunidad de responder ante sus conciudadanos y defenderse, mientras que en las víctimas tiene el significado

\footnotetext{
${ }^{26}$ Respecto a esto, tomo la sugerencia de Bentham de que, pese a que el fin general del castigo es la prevención del daño, pueden considerarse otros cuatro objetivos de tipo subordinado en los casos en que vale la pena imponer un castigo: el primer objetivo es prevenir hasta donde sea posible y valga la pena cualquier tipo de crimen, pero si un hombre decide que necesariamente debe cometer un crimen, el siguiente objetivo se orienta a que cometa la acción menos dañina; el siguiente objetivo se enfoca en que, una vez tomada la decisión de delinquir, se induzca al individuo a que no haga más daño del que sea necesario para obtener lo que pretende con el delito; el último objetivo consiste en que, cualquiera que sea el daño a prevenir, se debe hacer al menor costo posible (Bentham, 1996, p. 165).

${ }^{27}$ Atienza y Ruiz Manero señalan que las reglas de mandato, desde el punto de vista funcional, operan en el razonamiento práctico como imperativos categóricos, pues para quien acepta tales normas (por ejemplo, la que ordena al juez imponer tal pena en caso de asesinato) esto es una razón suficiente para actuar conforme a una regla. Por el contrario, las reglas que confieren poderes dan lugar a imperativos simplemente hipotéticos, es decir, razones para actuar siempre y cuando el sujeto pretenda alcanzar un determinado fin (un determinado resultado normativo) (2007, p. 92).
} 
simbólico de que se ha hecho justicia, porque otro ha sido llamado a responder por un daño indebido que ha sufrido. De esta manera, se abre la posibilidad de reivindicar sus intereses y se confirman los beneficios de la cooperación que legitima la propia práctica institucional del Derecho ${ }^{28}$. Por esto mismo, si la práctica en los tribunales cae en descrédito, el simbolismo reivindicatorio del juicio se pierde, amenazando la legitimidad del sistema de justicia penal (Gardner, 2012: 256).

El castigo, como ya se ha dicho, no ha de ser entendido como un instrumento de venganza, ni en modo alguno como una medida que permite restituir el mal que ha sido causado (a menos que asumamos la idea del bien metafísico que resulta de dos males). Por tanto, su existencia en nuestras sociedades no se justifica por el resarcimiento al dolor de las ya víctimas, sino por los beneficios preventivos (generales y especiales, positivos y negativos respectivamente) que pueden ser alcanzados a través de su aplicación. La distribución de castigos, sin embargo, exige recurrir a uno de los elementos relevantes en la concepción retribucionista: las penas deben ser aplicadas exclusivamente a los individuos que han violado una norma jurídica y que, en este sentido, son culpables. Por ello, cualquier sistema penal contemporáneo implica un compromiso especial con la justicia. Utilizando las palabras de Fletcher:

"Todos los sistemas de Derecho penal representan un compromiso compartido de absolver al inocente y castigar al culpable. Este compromiso les confiere un singular propósito unitario que está por encima y que se centra en la institución del castigo. Sin el castigo y sin las instituciones designadas para medirlo y ejecutarlo no habría Derecho penal. Es correcto decir, pues, que la institución del castigo ofrece la base de la que podemos esperar el nacimiento del Derecho penal y de sus elementos característicos" (Fletcher: 1997, 49).

Esta pretensión de justicia presupone que haya efectividad en el sistema penal, esto es, la justicia existe en la medida en que las víctimas y la sociedad en general puedan confiar, primero, en que quien ha cometido un delito -quien ha transgredido una regla y causado un daño- no quedará impune $y$, segundo, que quien ha observado el ordenamiento penal -quien sea inocente- no será castigado.

En este orden de ideas, la aplicación de castigos constituye una parte importante del sostén de las expectativas que se crean al vivir bajo un ordenamiento jurídico. Esto es así porque la práctica del castigo permite que, aun con casos de incumplimiento, el Derecho funcione y proteja los intereses más valiosos de los individuos. Por ello, se entiende que cuando estas expectativas quedan defraudadas se produce una especie de "abandono" a los ciudadanos (especialmente a las víctimas ${ }^{29}$ ), quienes quedan desprotegidos institucionalmente, teniendo que intentar proteger sus intereses de otra manera. Esta situación, a su vez, es perjudicial para la práctica del

\footnotetext{
${ }^{28}$ En este sentido, Antony Duff sostiene que el juicio penal emplaza al acusado a responder frente a una acusación formal por la comisión de un injusto público, a quien se llama para que participe como sujeto que debe responder por la comisión de un presunto delito; el acusado se declara culpable o inocente ante la autoridad del tribunal, reconociendo formalmente que este es el escenario frente al cual ha sido correctamente llamado a responder. Por esto es tan importante que el acusado sea apto para estar en el juicio, ya que se dirigen a él como agente responsable, esto es, alguien que puede responder acerca de los actos que se le formulan y, en su caso, responder jurídicamente por ellos (Duff, 2012, p. 153).

29 Sobre esto, nuevamente las palabras de Fletcher resultan esclarecedoras: "Cuando se deja sin perseguir y castigar a un delincuente violento, todos somos cómplices del mantenimiento del estado de servidumbre de la víctima... La práctica del castigo del delito ofrece a los conciudadanos de la víctima una oportunidad para expresar solidaridad y contraatacar la desigualdad producida por el delito. Cuando los ciudadanos no responden al delito, la víctima se siente sola, abandonada y traicionada por el sistema" (1997, p. 73).
} 
castigo, ya que se vuelve improbable que la disuasión del delincuente y de otros que aún no han delinquido sea efectiva.

Para cerrar este apartado quisiera enfatizar la idea del Derecho como práctica cooperativa que procura que las personas puedan desarrollar los planes de vida que se han propuesto. Sin embargo, la capacidad de una sociedad para lograr dinámicas de cooperación depende de diversos factores de tipo social, económico, cultural, etc. y este condicionamiento hace que en muchas ocasiones la sociedad desemboque en la anomia generalizada. Como veremos, la anomia puede comprometer gravemente el castigo como institución tendente a la prevención de delitos y a la protección de expectativas de cumplimiento entre los individuos de una comunidad.

\section{El problema de la anomia}

\subsection{La anomia general y la inobservancia de normas}

De entre las distintas dificultades que puede enfrentar una sociedad, es especialmente perjudicial la anomia general que resulta de la inobservancia de normas de distinto tipo ${ }^{30}$. La anomia general hace alusión a dinámicas de interacción entre los participantes de una sociedad que impiden desarrollar procesos de cooperación y llegar a resultados eficaces que beneficien los intereses generales e individuales de las personas. En contextos de anomia la preferencia dominante de los individuos resulta ser una que impide a los demás cumplir sus intereses. Los intereses generales terminan por verse frustrados, pero también los intereses propios -dado que los proyectos individuales necesitan de cierta estabilidad social y del respaldo institucional para poder cumplirse ${ }^{31}$. . Precisamente, las normas nos llevan a modificar nuestras preferencias, en la medida en que procuran que tengamos aquellas que favorecen la cooperación. Por ello, el incumplimiento masivo de normas jurídicas tiene consecuencias decisivas dentro de cualquier sociedad. Expliquemos esto.

En toda sociedad es previsible el incumplimiento de normas de conducta. Precisamente porque los individuos no somos ángeles ni demonios, el sistema jurídico contempla mecanismos -como el castigo- que permiten lidiar con cierto nivel de inobservancia. Es predecible, pues, que en cualquier dinámica social haya un número de individuos dispuestos a no seguir las normas de conducta establecidas, buscando satisfacer su autointerés. Al tiempo, y dentro de este mismo orden de ideas, el Derecho como práctica social puede soportar también cierto grado de incumplimiento por parte de las autoridades y, por ello, a menudo, hay órganos fiscalizadores que revisan si se ha hecho un uso incorrecto de potestades, ya sea negligente o intencionalmente, y las sanciones correspondientes para proteger el funcionamiento de las instituciones.

Esta tolerancia de cierto grado de ilegalidad está determinada por la propia estabilidad institucional del sistema jurídico-político; esto es, justamente, su

\footnotetext{
30 Podríamos decir que hay una situación anómica cuando los intereses de un grupo sólo son susceptibles de satisfacerse si todos sus integrantes cumplen con ciertas normas, pero un grupo significativo de individuos dentro de ese grupo social no cumplen con la mismas (Nino, 1992, p. 34).

${ }^{31}$ Este es el tipo de anomia que Nino califica como "boba", ya que, en principio, los individuos pretenden obtener un beneficio autointeresado que los lleva a desconocer los intereses colectivos, pero esto, a su vez, termina perjudicando los intereses individuales; es decir, que nadie resulta beneficiado (Nino, 1992).
} 
estabilidad y eficacia son las que permiten que no se vea afectado decisivamente. No obstante, hay situaciones en las que el incumplimiento de normas jurídicas deja de ser una excepción, provocando que las sociedades se vean envueltas en dinámicas institucionales anómicas, es decir, situaciones en las que normas jurídicas han dejado de ser observadas por un número tan elevado de individuos que también ha disminuido el compromiso institucional de hacerlas cumplir. Este es el sentido de la expresión "sociedades sin ley", sociedades en las que las normas y la estructura jurídica en general son fácticamente incapaces de garantizar a la sociedad un estado de armonía en el que los individuos puedan llevar a cabo sus planes de vida.

\subsection{La anomia en el ámbito del Derecho penal}

Sin duda, las dinámicas de las "sociedades sin ley" envuelven una fractura social profunda que se recrudece aún más cuando alcanza el nivel institucional, especialmente cuando se trata del sistema de impartición de justicia. Cualquier miembro de una comunidad jurídico-política necesita confiar en que no será dañado arbitrariamente 0 , al menos, en que se hará todo lo posible para evitar ese daño. Temer sobre lo anterior es perder una parte importante de nuestra tranquilidad para desarrollar la vida con normalidad y, asimismo, dudar sobre la capacidad de las autoridades para investigar y castigar determinadas conductas implica sentirse dentro de un sistema coactivo que no sólo no garantiza la prevención del daño, sino que tampoco garantiza la inmunidad frente al castigo cuando no se ha cometido ninguna transgresión jurídica.

Impunidad de los actos delictivos y falta de inmunidad ante el daño en caso de ser inocente serían así los ejes negativos que caracterizarían al castigo en un contexto anómico.

\subsection{Ciudadanos anómicos}

Tal y como se mencionada al inicio, dentro de la anomia general se da un grado de incumplimiento de normas jurídicas que afecta la estabilidad del sistema jurídico. La tendencia a la ilegalidad masiva repercute negativamente en la vida de todos los integrantes de un grupo social que requiere, necesariamente, de la cooperación. La mera desviación individual, como veíamos, es tolerable y tratable, pero la ilegalidad generalizada deviene en situaciones sociales disfuncionales en las que todos ven perjudicados objetivos e intereses valiosos.

Para entender adecuadamente en qué consisten estos perjuicios generados por la inobservancia masiva de normas jurídicas hay que considerar que la mayoría de ellas contienen prescripciones que procuran establecer pautas de justicia que coinciden con el contenido de normas morales ampliamente aceptadas. De esta forma, si las normas jurídicas en efecto reflejan principios válidos, su inobservancia generalizada constituye una frustración del valor de justicia (Nino, 1992: 37). Así, por ejemplo, parece razonable afirmar que la mayoría de los miembros de una comunidad estaríamos de acuerdo con una pauta de comportamiento que proscribe matar deliberadamente a otro. Casi todos estaríamos dispuestos a suscribir que quien -en condiciones normales- ha decidido matar a otro individuo debe ser presentado ante las autoridades correspondientes para dar lugar a un procedimiento que determine su responsabilidad y su castigo. Serían muy pocos los individuos dispuestos a sostener seriamente que normas como esta no protegen algo valioso y que, por tanto, su incumplimiento no debería tener consecuencia alguna. 
Por ello cuesta tanto intentar entender desde un punto de vista racional colectivo ${ }^{32}$ ciertas dinámicas que se dan en las sociedades sin ley, puesto que esas dinámicas involucran concesiones a las que conscientemente nadie querría renunciar; un gran problema en este punto es, precisamente, que no hay un ejercicio consciente de renuncia por parte de los ciudadanos anómicos. Lo que pretendo destacar con esto es que la ilegalidad general no sólo implica un comportamiento hacia las normas, sino que lo anterior se acompaña de una actitud de desprecio hacia ellas que implica ignorancia y negligencia hacia los fines valiosos que pretenden conseguirse a través de las mismas.

En efecto, se están ignorando las finalidades perseguidas por las normas jurídicas sin percibir de forma consciente el daño social que su incumplimiento conlleva. Este incumplimiento convierte a todos los miembros de una comunidad en víctimas de una desconfianza general que se refleja en distintos niveles de las relaciones sociales y que, evidentemente, se refleja también en el funcionamiento de las instituciones.

\subsection{Instituciones anómicas}

La tendencia a la ilegalidad generalizada es un gran obstáculo para que el Derecho pueda cumplir con sus principales cometidos, pero, sin duda, esta tendencia por parte de las autoridades representa un caso de deslealtad a los valores que subyacen al sistema jurídico especialmente perjudicial. Las autoridades anómicas incumplen deberes que involucran intereses colectivos, provocando la frustración de los fines que se pretenden alcanzar a través de las instituciones jurídicas. El mal uso de potestades, aunque con beneficios inmediatos para algunos -por ejemplo, un provecho de tipo económico-, debilita y desacredita el sistema de justicia.

Esta deslealtad a los principios del sistema jurídico por parte de autoridades se manifiesta de diversas maneras y, aunque la más común y quizá la más grave, suela ser la corrupción, no se limita a esta ${ }^{33}$. Puede suceder también que se realice la conducta indicada por la norma pero que esto represente más bien un ejercicio ritualista en el que se observa la ley pero se ignoran los objetivos sociales. En este sentido, Nino señala que comportamientos como éste distinguen la conducta burocrática, esto es, la de quienes se adhieren a la norma sin consideración a los fines por los que fue dictada, ya sea porque asumen que la norma es un fin en sí misma, o un medio para fines de otro tipo, como el lucro personal o el ejercicio de poder sobre otros (Nino, 1992: 42).

En línea con este tipo de consideraciones, Nino señala que podemos identificar dos tipos de actitudes de los funcionarios para - pretender- justificar un uso cuestionable de sus facultades. Por un lado, actitudes que enfatizan el carácter imperativo de fines personales y, por el otro, actitudes formalistas que llevan a las autoridades a aplicar e interpretar las normas jurídicas sin tomar en cuenta los fines que éstas procuran satisfacer (Nino, 1992). Una actitud finalista, que no tenga en cuenta fines de tipo colectivo, favorece la toma decisiones de manera aislada, esto es, sin tomar en cuenta las prácticas sociales. Así, por ejemplo, actúa de esta forma el funcionario

\footnotetext{
${ }^{32}$ No así desde una racionalidad individual, desde la cual tiene sentido que una persona se comporte de determinada forma para satisfacer su autointerés.

${ }^{33}$ Rodolfo Vázquez señala que la corrupción tiene gran parte de responsabilidad en la crisis o anomia generalizada en el nivel institucional. Respecto a ésta, sugiere que tengamos en cuenta lo siguiente: es un fenómeno de carácter permanente, es decir, que existe en cualquier sistema político y es ilusorio pensar que se la puede erradicar del todo; la corrupción no es exclusiva de aquellos regímenes políticos no evolucionados o desarrollados, así como tampoco de ciertos sectores sociales; la corrupción está vinculada lógicamente a un sistema normativo, por lo que no es sólo un fenómeno político, aunque su dimensión pública es distinta y tiene una importancia particular (2007, p. 207 y 208).
} 
que utiliza su cargo para favorecer a un familiar, al considerar que la finalidad de ayudar a sus allegados es suficientemente valiosa como para justificar el mal uso de sus funciones. Por su parte, la actitud formalista es también muy peligrosa, ya que pretende dar la sensación de que se está preservando la seguridad jurídica por medio de un seguimiento estricto del Derecho positivo. Esta actitud lo que hace es encubrir decisiones inadecuadas y darles la apariencia de legalidad, sin tomar en cuenta criterio material alguno y suprimiendo la posibilidad de discutir y posicionarse abiertamente sobre un posible disenso moral entre el caso concreto y la enunciación de la norma.

Con una actitud formalista como la descrita se cometen atrocidades que pretenden ocultarse aludiendo a la letra del Derecho positivo, mostrando a los funcionarios como simples seguidores de la ley sin responsabilidad sobre los resultados de sus decisiones. Sin embargo, las normas jurídicas, como bien se sabe, requieren ser interpretadas, lo que implica una reconstrucción valorativa que no puede satisfacerse aludiendo simplemente a la ley o a la autoridad. De esta forma, en el caso del castigo, fundamentar una pena conforme al Derecho no consiste sólo en establecer cuáles son las normas que llevan aparejada dicha sanción, sino que es necesario explicitar por qué los materiales han sido interpretados de la forma en que lo han sido, a la luz de los valores protegidos. Las autoridades, entonces, son agentes morales, lo que implica que son moralmente responsables del desenlace de sus decisiones.

Siguiendo con las reflexiones acerca de la anomia a nivel institucional, es necesario destacar que la misma frustración de intereses que se da en la anomia general se presenta en las instituciones cuando los funcionarios no cumplen con sus potestades de forma adecuada o cuando no tienen la certeza de que otros harán lo que les corresponde. En este nivel, las dinámicas anómicas afectan de forma directa las finalidades de las instituciones. En particular, en el castigo se hace más evidente que se requiere de un aparato coactivo que funcione correctamente, y para ello es indispensable la cooperación y coordinación entre funcionarios. La práctica de castigar requiere que las distintas autoridades que intervienen en su determinación y ejecución estén coordinadas y se ayuden entre sí, puesto que, incluso cuando unos cumplan sus funciones de la mejor manera, el resultado siempre se verá perjudicado si otros no lo hacen.

Cuando el mal funcionamiento de la institución del castigo se normaliza, podemos destacar dos graves consecuencias (además de las consecuencias negativas inmediatas que, por supuesto, tiene sobre los sujetos afectados): la primera de ellas es que la percepción social del castigo se ve profundamente afectada. Con esto me refiero a que la anomia institucional refuerza la actitud poco cooperativa de los ciudadanos, quienes se convencen de que al no poder confiar en las instituciones, les corresponde hacer todo lo necesario para proteger sus intereses por sí mismos, ya que no hay nadie que los respalde. Por otro lado, la anomia institucional pone en peligro la continuidad de la práctica estabilizadora de expectativas de cumplimiento que permite proteger intereses valiosos de los individuos, y en un contexto como este, justificar la institución del castigo que sigue operando se vuelve doblemente complicado. Lo anterior será mejor desarrollado a continuación. 


\section{Sociedades anómicas y sus -graves- consecuencias en la justificación del castigo. Conclusiones}

Como ya se anunciaba, la anomia tiene claras repercusiones en el desenvolvimiento y viabilidad de la práctica normativa general y, claro está, en la del castigo. Ningún sistema jurídico puede autosustentarse ${ }^{34}$ y lo que sucede de facto termina afectando la percepción que los individuos tienen de las penas. $Y$ es que, en efecto, para los ciudadanos resulta cada vez más difícil confiar en la legitimidad de las normas penales y de la institución del castigo. Si bien no es posible dar una visión precisa de la percepción que se tenga de la misma hay muchos estudios estadísticos que hacen un gran esfuerzo por medir la impunidad (transgresiones jurídicas sin castigo) de distintos países y que pueden orientarnos acerca de tal percepción. Estos estudios suelen tomar en cuenta los siguientes casos: delitos no denunciados; delitos que se denuncian, pero no llegan a ser investigados; delitos que, pese a ser investigados, llegan a sentencias injustas; o penas que nunca llegan a ser ejecutadas.

Aunque estos estudios estadísticos pueden ser útiles, es necesario tener en cuenta que existen muchas limitaciones en cuanto a la información, ya que nunca es completa ni del todo confiable; muchas veces proviene de los propios informes de los gobiernos que "maquillan" los datos reales para evitar dar una mala impresión o, sencillamente, porque es materialmente imposible llegar a saber con certeza cuántos delitos se llevan a cabo. Sin embargo, estos esfuerzos son muy valiosos para dimensionar la crisis de impunidad a la que nos enfrentamos ${ }^{35}$.

En muchos países, como el ejemplo citado al inicio de este trabajo, la existencia de una anomia generalizada es evidente, por lo que las estadísticas son sólo el reflejo de una situación que se vive como normal. La ilegalidad es omnipresente y la sociedad se ve obstaculizada para desarrollarse en distintas áreas como la política, la económica y la jurídica. En el caso del Derecho, sus funciones principales -evitar los conflictos y facilitar la cooperación- se ven seriamente limitadas o incluso se convierten en un obstáculo para la vida de las personas, para quienes puede resultar mucho más costoso, en términos de esfuerzos y recursos, cumplir con las normas jurídicas que buscar caminos alternativos.

La actitud de desprecio que los ciudadanos tienen hacia las normas es una proyección de la decepción que se tiene por las instituciones y sus funcionarios. Al tiempo, no podemos olvidar que en otros contextos los funcionarios son también ciudadanos. En la medida en que la vida social y la institucional no están separadas el anómico manejo del poder público se convierte en -mal- ejemplo e inspiración del comportamiento anómico generalizado (Nino, 1992: 87).

\footnotetext{
${ }^{34}$ Aunque un sistema jurídico suela ser eficaz para respaldar las normas jurídicas que lo integran no puede auto-sustentarse, debido a que no es posible que exista siempre un órgano que vigile jurídicamente el funcionamiento de otro. Las razones finales necesariamente son de tipo moral, puesto que las normas morales no dependen de la aceptación de una autoridad; son razones de este tipo las que nos permiten justificar una acción o decisión. El Derecho, visto como práctica colectiva, para llegar a resultados eficaces en la cooperación necesita apoyarse en la moral.

${ }^{35}$ El Centro de Estudios Sobre Impunidad y Justicia (CESIJ) de la Universidad de las Américas (Puebla) elaboró en 2015 un índice de impunidad global, el cual tomó en cuenta a 59 países y determinó los siguientes resultados sobre los países del llamado "mundo latino": México ocupó el segundo puesto en impunidad, Colombia el número 3 , Nicaragua el $6^{\circ}$ puesto, Honduras el $7^{\circ}$, El Salvador el $8^{\circ}$, Argentina el $11^{\circ}$, Chile el puesto $14^{\circ}$, España el $17^{\circ}$, Panamá el $22^{\circ}$, Paraguay el $24^{\circ}$, etc. Además, en los países de América Latina se detectaron mayores problemas en términos de estructura de seguridad y de impartición de justicia. Para consultar más información: http://udlap.mx/cesij/files/IGI 2015 digital.pdf
} 
Con lo anterior no se pretende sugerir algo tan ingenuo, o tan perverso, como que todos somos culpables de nuestra desgracia y que el cambio individual tendrá como consecuencia la superación de la anomia. La responsabilidad pesa más sobre unos que sobre otros, dependiendo del rol asumido en la sociedad: es innegable que la responsabilidad de los funcionarios es distinta que la del simple ciudadano. Además, siguiendo con estas ideas, que un individuo concreto decida hacer lo correcto no puede lograr "mágicamente" que los demás hagan lo mismo, aunque, paradójicamente, actuar correctamente por razones de principios -confiando en que muchos, al menos hipotéticamente, actúen igualmente- es algo necesario para mantener vigentes pautas de conducta como las penales, que tienen detrás un referente ético que puede haberse perdido o ensombrecido por las circunstancias imperantes. Si bien lograr cambiar la tendencia hacia la ilegalidad es algo mucho más complejo y sería seguramente ilegítimo pedirle a los ciudadanos que asuman el papel de héroes dispuestos a cumplir con las normas a pesar de las enormes desventajas que esto supone en los sistemas anómicos, quizás esas mismas exigencias de comportamiento ejemplarizante sí puedan ser exigibles a las instituciones y a quienes desempeñan funciones dentro de las mismas ${ }^{36}$.

En lo que respecta al sistema penal es fundamental atender a estas desventajas y remover obstáculos para incentivar la participación de los ciudadanos en el proceso de impartición de justicia ${ }^{37}$. La institución de la pena sólo tiene sentido en un escenario de buen funcionamiento del sistema penal en el que los ciudadanos tienen seguridad jurídica. Para ello es indispensable revertir la anomia. Asimismo, es importante hacer notar otra consecuencia, ya mencionada, que tiene la anomia sobre el castigo: en contextos anómicos, la institución no sólo pierde su fuerza por la mala percepción social y moral que se tiene de ella, sino que se pone en peligro su justificación general, ya que no se está cumpliendo con el propósito de prevenir el daño entre los individuos. En las sociedades sin ley la reflexión sobre la justificabilidad de la institución pierde sentido porque no es posible demostrar que hay un mal mayor que se está evitando, así como tampoco existe la certeza de que se esté castigando a aquellos individuos que son culpables de una transgresión.

El panorama que nos arrojan las cifras de personas que sufren daños arbitrariamente y que quedan impunes es desolador; con esto se muestra que estamos cerca de poder afirmar la ineficacia del castigo y el fracaso en la obtención de su finalidad general. Y el gran problema es que, de determinarse esa ineficacia, se pone en duda su legitimidad y el papel que desempeña dentro de la sociedad. Algo que resulta muy preocupante es que, a pesar de su fracaso -o del serio cuestionamiento de su eficacia-, sigue operando como práctica punitiva, es decir, que se está permitiendo que algunos individuos -quizás ni siquiera aquellos que son

\footnotetext{
${ }^{36}$ Por supuesto, bien puede suceder que los propios funcionarios que tienen la adecuada actitud hacia la norma y la institución se encuentren de hecho obstaculizados por la propia anomia generalizada dentro de la institución.

${ }^{37}$ Para atender a tales desventajas y obstáculos puede resultar útil la función promocional del Derecho. Tal como se anotaba antes, Pérez Lledó sugiere que es posible distinguir entre premio puro, promesa de premio, incentivo puro y facilitación. En mi opinión, el incentivo puede ser una categoría útil en la contienda contra la anomia. Así, por ejemplo, ofrecer una reducción de la pena por cooperar con la justicia y denunciar a cómplices $u$ ofrecer información relevante puede ser un incentivo que motive directamente la conducta del individuo. Por otra parte, las facilitaciones motivan la conducta pero sólo indirectamente, ya que facilitan o promueven conductas que, de otra forma, sería muy difícil realizarlas, por lo que funcionan removiendo obstáculos para los ciudadanos. Por ejemplo, en el caso de las denuncias, se podría dar una facilitación eliminando el peligro que implica denunciar a través de la posibilidad de denuncias anónimas o proporcionando seguridad a quienes denuncian. Lo importante es que las facilitaciones no pretenden otorgar una razón operativa, sino que intentan proporcionar al destinatario los medios necesarios para hacer posible o menos gravosa la conducta. Además, estas facilitaciones suelen estar vinculadas a cuestiones de coordinación de conductas (Pérez Lledó, 2000, p. 683).
} 
culpables de un delito- padezcan castigos sin un mal considerablemente mayor que se esté evitando. Así, una gran cantidad de individuos que "merecen" un castigo, en el sentido de ser culpables de haber transgredido una norma jurídica, no están recibiendo ese castigo por motivos injustificados como el mal funcionamiento o la arbitrariedad dentro del sistema de justicia, a la par que otros individuos están sufriendo un castigo que no merecen. Sin duda esto es algo que requiere de una reflexión mucho más profunda.

Por mi parte, he pretendido hacer notar la importancia de profundizar en este tema y atender a esta importante consecuencia que, según parece, se avecina en nuestras prácticas punitivas ${ }^{38}$; al tiempo, he querido expresar las dificultades a la que nos enfrentamos al reflexionar sobre la justificación de la pena en contextos en los que no se cuenta con el presupuesto de estabilidad institucional. En primer lugar, sin una adecuada percepción social y moral sobre el castigo, este no puede funcionar como técnica de motivación de la conducta de los individuos, puesto que es indispensable que las personas tengan la certeza de que el castigo se hará efectivo en el supuesto de transgredir una norma, así como la seguridad de que se permanecerá inmune ante él si las mismas se observan. En segundo lugar, pese a que el castigo está presente en prácticamente todas nuestras sociedades, tenemos el compromiso de su fundamentación, ya que se trata de una institución moralmente cuestionable que no podemos aceptar sin más. Históricamente parece que conservamos la institución de la pena porque consideramos que a través de ella podemos evitar un mal tan grande como la comisión ilimitada de conductas delictivas. Si llega el momento en que se demuestre que ese mal mayor no existe, o que el mal evitado no es lo suficientemente mayor, habremos perdido una de las razones más fuertes que sustentan la fundamentación del mal del castigo como mal menor.

Frente a estos escenarios en los que el daño ha llegado a ser tan habitual como para ser menospreciado, insistir en la importancia sobre la deliberación en torno al castigo institucionalizado es uno de los primeros pasos que deben tomarse para restablecer la conciencia de juridicidad y poder aspirar, de manera realista, a un futuro mejor. Además, hay que recordar que el Derecho es, entre otras cosas, un mecanismo de transformación social, de cambio de hábitos y preferencias, pero para generar esas transformaciones es necesario realizar importantes reformas jurídicas que permitan asegurar la efectividad de las sanciones, de los procesos de aplicación del Derecho y la transparencia en la gestión de las administraciones públicas $^{39}$. Un nivel aceptable de prevención no se consigue al aumentar los montos de las penas, castigando a más individuos, facilitando los procesos, o buscando mecanismos alternativos para castigar a alguien ${ }^{40}$. Este nivel de prevención sólo se

\footnotetext{
${ }^{38}$ Así, no me parece que sea una coincidencia el número, cada vez mayor, de partidarios del abolicionismo de penas como la prisión, quienes reclaman que la prisión es un medio ineficaz que conlleva un sufrimiento excesivo para quienes la padecen.

${ }^{39}$ Las normas jurídicas son necesarias para evitar y para solucionar problemas de coordinación, pero esto no significa que tales normas efectivamente existan o vayan a existir en una sociedad. Los procesos anómicos pueden impedir que tales normas emerjan o que puedan llevarse a cabo, ya que la situación que se pretende resolver puede ser precisamente su mayor impedimento; aun así, indudablemente, la mayoría de las situaciones de ineficacia social requieren de normas para poder superarse (Nino, 1992).

${ }^{40}$ Respecto a lo anterior resulta interesante la observación de Taruffo acerca de las manifestaciones de la crisis de funcionalidad de la ley procesal. Este autor señala la generalidad de la crisis de efectividad de la tutela jurisdiccional, la cual, deriva de los retrasos de la justicia. Esto conlleva consecuencias negativas relevantes, como el que cada vez sean más numerosas las áreas en las que no se administra realmente una justicia aceptable, así como el hecho de que la gente tenga la percepción de que la elección más racional del titular de un derecho es no hacerlo valer en juicio por el tiempo excesivo que implica. Así, "se produce una sustancial elusión de la necesidad de tutela procesal y se vuelven ineficaces las garantías de acceso a los tribunales que están recogidas en numerosas Constituciones contemporáneas" (Taruffo, 1999, p. 315). Sin embargo, esta crisis de funcionalidad
} 
puede alcanzar cuando la institución es eficaz, permitiendo que la certeza del castigo juegue un papel en la deliberación de las personas. Todo lo anterior presupone la existencia de una firme voluntad política que reconozca los niveles de anomia que han llegado a afectar a nuestras sociedades, comprometiéndose a realizar un fuerte cambio en las instituciones y en quienes directamente las hacen funcionar.

En definitiva, aunque el problema de la anomia es mucho más complejo de lo que puede tratarse aquí, he pretendido llamar la atención sobre las graves consecuencias que tiene sobre la institución del castigo la ineficacia del sistema jurídico. Asimismo, he intentado mostrar que, si asumimos que los individuos son agentes morales racionales, debemos rechazar cualquier análisis de la anomia en clave determinista que nos lleve a concluir que en algunos países los individuos están condenados a ser desleales ${ }^{41}$. Finalmente, es oportuno insistir en la relevancia de que se tome conciencia de las consecuencias negativas de que se ignoren los perjuicios que esta situación produce en la vida de las personas, así como pensar en estrategias que faciliten el cumplimiento de nuestros deberes jurídicos y morales.

\section{Bibliografía}

ALEMANY, Macario (2006). El concepto y justificación del paternalismo, Editorial lustel, Madrid.

ATIENZA, Manuel y RUÍZ MANERO, Juan (2007). Las piezas del Derecho: teoría de los enunciados jurídicos, Ariel, Barcelona.

BENTHAM, Jeremy (1996). An Introduction to the Principles of Morals and Legislation, Clarendon Press, Oxford.

CENTRO DE ESTUDIOS SOBRE LA IMPUNIDAD Y JUSTICIA, Universidad de las Américas Puebla (México), índice global de impunidad 2015, disponible en la siguiente dirección electrónica: http://www.udlap.mx/cesij/Default.aspx (fecha de consulta: 6 de abril de 2016).

COSSíO, José Ramón. "La impunidad en México es un problema creciente".

Disponible en la siguiente dirección:

http://internacional.elpais.com/internacional/2015/10/22/actualidad/1445526786 256 545.html (fecha de consulta 15 de abril de 2016).

DÍEZ RIPOLLÉS, José Luis (2011). "Presupuestos de un modelo racional de legislación penal". Doxa: Cuadernos de filosofía del Derecho, no. 24, pp. 485-523.

\footnotetext{
también se manifiesta en los innumerables esfuerzos por encontrar formas "alternativas" de solución de controversias. Sobre esta tendencia, el autor señala que, contrario a lo que muchos piensan, el uso creciente de las formas alternativas de justicia no es un factor positivo, sino la señal evidente de la crisis de la justicia ordinaria: es un signo de patología del sistema procesal. Asimismo, no todo es bueno en el ámbito de estas alterativas de solución de controversias, ya que muchas veces implican serios inconvenientes, injusticias, degeneraciones y desigualdades en su funcionamiento; por ello, no es conveniente depositar en estos mecanismos una confianza indiscriminada (Taruffo, 1999, p. 316).

${ }^{41}$ Incluso en este caso, si los individuos estuvieran determinados a incumplir las normas, el castigo podría seguir motivando el comportamiento de los seres humanos, aunque ya no como individuos reflexivos, sino como simples seres aptos al condicionamiento más básico de evitar dolor.
} 
DUFF, R. A. (2012). "Responsabilidad y punibilidad en Derecho penal", Kramer, Grant, Colburn, Hatzistavrou (comps.) El legado de H.L.A. Hart: Filosofía jurídica, política y moral, Madrid, Marcial Pons, pp. 145-163.

DURKHEIM, Émile (1982). La división del trabajo social, Akal, Madrid.

ENCUESTA NACIONAL DE VICTIMIZACIÓN Y PERCEPCIÓN SOBRE SEGURIDAD PÚBLICA (ENVIPE) (México), encuesta de 2015, disponible en la siguiente dirección electrónica:

http://www.inegi.org.mx/est/contenidos/proyectos/encuestas/hogares/regulares/envip e/envipe2015/default.aspx (fecha de consulta: 4 de abril de 2016).

FERRAJOLI, Luigi (1995). Derecho y razón. Teoría del garantismo penal, Editorial Trotta, Madrid.

FINNIS, John M. (1999). "Retribution: Punishment's Formative Aim", Journal Articles Notre Dame Law School, pp. 99-103.

GARDNER, John (2012). Ofensas y defensas: Ensayos selectos sobre filosofía del Derecho penal, Marcial Pons, Madrid.

HART, H. L. A (2011). El Concepto De Derecho. $3^{\circ}$ reimp., Abeledo-Perrot, Buenos Aires.

--- (2008). Punishment and Responsibility: Essays in the Philosophy of Law. $2^{\circ}$ ed., Oxford University Press, Oxford.

GONZÁLEZ LAGIER, Daniel (2015) (coord.). Conceptos básicos del Derecho, Marcial Pons, Madrid.

MACCORMICK, Neil (2010). H. L. A. Hart, Marcial Pons, Madrid.

NINO, Carlos Santiago (1992). Un país al margen de la ley: estudio de la anomia como componente del subdesarrollo argentino, Emecé Editores, Buenos Aires.

--- (1983) Introducción al análisis del Derecho, Ariel, Barcelona.

--- (1980) Los límites de la responsabilidad penal, Astrea, Buenos Aires.

--- (1994) Derecho, moral y política, Ariel, Barcelona.

--- (1989) Ética y derechos humanos. Un ensayo de fundamentación, Ariel Barcelona.

--- (2006) Juicio al mal absoluto, Ariel, Buenos Aires.

PÉREZ LLEDÓ, Juan Antonio (2000). "Sobre la función promocional del Derecho: un análisis conceptual”, Doxa: Cuadernos de filosofía del Derecho, no. 23, pp. 665-687.

RABOSSI, Eduardo (1976). La justificación moral del castigo, Astrea, Buenos Aires.

ROXín, Claus (1976). Problemas básicos del Derecho penal, Reus, Madrid.

ROSS, Alf (1994). Sobre el Derecho y la justicia. 5ta ed., Editorial Universitaria de Buenos Aires, Buenos Aires. 
SILVA SÁNCHEZ, Jesús María (2011). "Prevención del delito y reducción de la violencia", Ita ius esto, no. 2, pp. 27-40.

TARUFFO, Michele (1999). "Racionalidad y crisis de la ley procesal", Doxa: Cuadernos de filosofía del Derecho, no. 22, pp. 311-320.

VÁZQUEZ, Rodolfo (2007). Corrupción política y responsabilidad de los servidores públicos", Doxa: Cuadernos de filosofía del Derecho, no. 30, pp. 205-216. 